\title{
Utilization of Google Class Room in improving learning quality for lecturers and students at the USU department of biology FMIPA
}

\author{
Suci Rahayu ${ }^{1 *}$, Nursahara Pasaribu ${ }^{1}$, Elimasni $^{2}$, Emita Sabri $^{3}$, Denny Supriharti ${ }^{4}$ \\ ${ }^{1}$ faculty of mathematics and science, Universitas Sumatera Utara, Medan, Indonesia \\ *Email: suci_bio85@yahoo.co.id
}

\begin{abstract}
Community service activities titled Transforming Organic Waste into Organic Fertilizer in Namo Bintang Village in May - November 2019. This activity aims to convert organic waste into organic fertilizer that has economic value, and does not endanger the environment. The method used is counseling, lectures and training as well as monitoring and evaluation with the community directly to the field. Utilization of Google Class Room is done in several places in the Biology department with the approval of the Chair of the Department. The activity was carried out by means of counseling and lectures, explaining the theory and techniques of using Google Class Room, which was followed by a group of Lecturers and Students in the Biology department at USU FMIPA.The training was conducted by a group of Lecturers and Students in the Biology department of USU FMIPA separately. All carry out this activity by proactively conducting training to get results in the form of the Google Class Room application. The equipment for using Google Class Room is only a laptop, smartphone and internet package. And finally the monitoring and evaluation of the success of monitoring work in the field will be carried out by going directly to the field together, monitoring by visiting to find out whether lecturers and students have been able to do it themselves. In addition, the relationship will be carried out by telephone to overcome the problems that arise. In general, community service activities have been successfully carried out and seen a good cooperative relationship between the Higher Education, especially the Implementation Team, the village community realizes the importance of saving the environment from at the same time improving life expectancy because it can make its own fertilizer / compost.
\end{abstract}

Keyword: Change, Organic Trash, Organic Fertilizer, Namo Bintang Village

\begin{abstract}
Abstrak
Kegiatan pengabdian pada masyarakat dengan judul Mengubah Sampah Organik menjadi Pupuk organik di Desa Namo Bintang pada bulan Mei - November 2019. Kegiatan ini bertujuan mengubah sampah organik menjadi pupuk organik yang memiliki nilai ekonomis, dan tidak membahayakan bagi lingkungan hidup. Metode yang digunakan adalah penyuluhan, ceramah dan pelatihan serta monitoring dan evaluasi bersama masyarakat langsung ke lapangan. Pemanfaatan Google Class Room dilakukan di beberapa tempat di departemen Biologi dengan persetujuan Ketua Departemen. Pelaksanaan kegiatan dilakukan dengan cara penyuluhan dan ceramah, penjelasan teori dan teknik pemanfaatan Google Class Room yang diikuti kelompok Dosen dan Mahasiswa departemen Biologi FMIPA USU. Pelatihan dilakukan oleh kelompok Dosen dan Mahasiswa di departemen Biologi FMIPA USU secara terpisah. Semua melakukan kegiatan ini dengan proaktif melakukan pelatihan untuk mendapatkan hasil berupa aplikasi Google Class Room.. Peralatan untuk pemanfaatan Google Class Room hanya laptop, smartphone dan paket internet. Dan terakhir monitoring dan evaluasi keberhasilan pemantauan pekerjaan di lapangan akan dilakukan dengan turun langsung ke lapangan secara bersama-sama, pemantauan dengan kunjungan untuk mengetahui apakah dosen dan mahasiwa sudah bisa melakukan sendiri, Selain itu hubungan akan dilakukan lewat telepon untuk mengatasi masalah-masalah yang timbul. Secara umum kegiatan pengabdian pada masyarakat ini berhasil dilakukan dan terlihat adanya hubungan kerjasama yang baik antara Perguruan Tinggi khususnya Tim Pelaksana, Masyarakat desa menyadari pentingnya menyelamatkan lingkungan dari sekaligus meningkatkan tarap hidup karena sudah dapat membuat pupuk /kompos sendiri.
\end{abstract}

Kata Kunci: Mengubah, Sampah Organik, Pupuk Organik, Desa Namo Bintang 


\section{PENDAhuluan}

Modernisasi teknologi itu juga tidak hanya merambah dunia perdagangan saja melainkan teknologi sudah mulai merambah dunia pendidikan. Dunia pendidikan sudah mulai meninggalkan pembelajaran secara luring. Dunia pendidikan saat ini sudah mulai mengarah kepada pembelajaran yang mengarah kepada pembelajaran secara daring. Melalui pembelajaran secara daring, maka diharapkan mahasiswa dapat lebih mengembangkan kemampuannya ke arah yang lebih baik. Salah satu kemampuan yang diharapkan dapat berkembang secara lebih baik adalah kemampuan pemecahan masalah. Kemampuan pemecahan masalah amatlah penting, bukan saja bagi mereka yang di kemudian hari akan mendalami atau mempelajari suatu ilmu, melainkan juga bagi mereka yang akan menerapkannya dalam bidang studi lain dan dalam kehidupan sehari-hari (Fadillah. 2009). Google Classroom sebagai salah satu aplikasi yang berbasis pendidikan, tentunya sangat membantu jalannya proses belajar dan mengajar.

Google classroom sangat bermanfaat bagi pendidikan dalam menghadapi kemajuan teknologi dan informasi. Banyak metode mengajar yang diterapkan dosen, namun setiap dosen, tentunya tidak sama dalam menghadapi persoalan yang terjadi terhadap mahasiswa. Manfaat dari adanya google classroom tentunya banyak sekali. Sebagai sarana memperlancar komunikasi antara mahasiswa dengan dosen atau dosen. Aplikasi ini juga berguna untuk mahasiswa belajar, menyimak, membaca, mengirim tugas, dari jarak jauh. Kita sebagai pelajar, smartphone kita jangan hanya diisi dengan game permainan dan media sosial. Usahakanlah Smartphon kita berguna terhadap proses belajar kita.

Adanya Google Classroom sebagai aplikasi Android khusus untuk dunia pendidikan sangat mendukung terhadap kegiatan belajar dan mengajar. Agar lebih praktis, hemat waktu. Dan membantu para dosen menciptakan dan mengumpulkan tugas dari mahasiswa. Aplikasi Google Classroom ini juga menciptakan folder drive untuk setiap tugas mahasiswa. membantu dan menjaga semua dokumen secara terorganisir. Google Classroom adalah produk google yang terhubung dengan gmail, drive, hangout, youtube dan calendar yang dalam. Banyaknya fasilitas yang disediakan google classroom akan memudahkan dosen dalam melaksanakan kegiatan pembelajaran. Pembelajaran yang dimaksud bukan hanya di kelas saja, melainkan juga di luar kelas karena peserta didik dapat melakukan pembelajaran dimana pun dan kapan pun classroom secara online.

Google class room adalah suatu learning management system yang dapat digunakan untuk menyediakan bahan ajar, tes yang terintegrasi penilaian. Berbeda dengan media pembelajaran yang lain keunggulan media google class room adalah masalah efektifitas dan efisiensi dalam pembelajaran.

Di Departemen Biologi FMIPA USU beberapa dosen sudah mengunakan google classroom, namun jumlahnya sangat sedikit dibanding yang belum mengunakannya. Mahasiswa yang mengunakannya juga tidak banyak hanya pada mata kuliah tertentu saja, dan itupun masih ada yang kurang mengerti dalam mengunakannya. Padahal pembelajaran dengan mengunakan google clasroom metodenya sangat efisien dan efektif. Dengan pemanfaatan gooole classroom diharapkan akan meningkatkan mutu pembelajaran di departemen Biologi FMIPA USU. Dan untuk memudahkan capaian akreditas departemen FMIPA USU..

\section{METODE PELAKSANAAN}

Metode yang digunakan dalam kegiatan ini adalah gabungan antara penyuluhan, pelatihan, praktek langsung serta evaluasi kerja. Kegiatan ini didukung oleh Ketua Departemen akan berperan membantu pelaksanaan ini dengan memberikan izin, menghubungi dosen dan mahasiswa. Sedangkan manfaat yang diperoleh akan meningkatkan pengetahuan sumberdaya manusia dalam hal Pemanfaatan Google Classroom. 
Dalam pengabdian ini kelompok dosen dan mahasiswa dilatih dalam penggunaan google classroom dari staff UMM (Unit Mangement Mutu) USU yaitu Bapak Riyanto Sinaga, S.Si, M.Si dilakukan secara terpisah antara kelompok dosen dan mahasiswa agar kedua kelompok lebih leluasa dalam pelatihan tersebut. Pemanfaatan Google Classroom dalam Peningkatan Mutu Pembelajaran bagi Dosen dan mahasiswa di Departemen Biologi FMIPA USU dengan pemanfaatan google classroom dapat melalui multiplatform yakni melalui komputer dan telepon genggam. Dosen dan mahasiswa dapat mengunjungi situs https://classroom.google.com atau mengunduh aplikasi melalui playstore di android atau app store di iOS dengan kata kunci google classroom. Penggunaan LMS tersebut tanpa dipungut biaya, sehingga pemanfaatannya dapat dilakukan sesuai kebutuhan.

Dalam pemanfaatan google classroom sangat mudah, praktis, ekonomis, dan murah, hanya memerlukan beberapa waktu dan siapapun dapat melakukannya. Untuk lebih jelasnya pemanfaatan google classroom di Deppartemen Biologi FMIPA USU adalah sebagai berikut :

Pemanfaatan Google Classroom

a. Dosen

Cara mengakses google classroom yang paling mudah adalah lewat playstore kita ketikkan google classroom, download aplikasinya, buka dan instal di laptop atau handphone masingmasing. Bentuk tampilan yang muncul di HP adalah persegi warna hijau dengan tulisan google class room. Setelah berhasil didownload, dibuka dan diinstal google class room dapat dimulai dengan mengklik tanda "+" yang ada pada toolbar bagian atas. Ada dua opsi yang akan muncul yaitu membuat kelas dan gabung kelas. Dosen dapat membuat kelas dengan mengetik nama kelas, mata pelajaran dan subyek belajar yang dihadapi.

Untuk memulai menggunakan google class room bagi dosen terlebih dahulu masuk dalam akun google dan kemudian mencari produk google tersebut. setelah masuk pada akun google classroom kita dihadapkan pada tiga menu utama yaitu stream /aliran, classwork/aktifitas mahasiswa dan people. Stream adalah fasilitas google class yang dapat digunakan untuk membuat pengumunan, mendiskusikan gagasan atau melihat aliran tugas, materi, quiz dari topik-topik yang diajarkan dosen. Classwork dapat digunakan dosen untuk membuat soal tes, pretes, quiz ,menggunggah materi dan mengadakan refleksi. Pada menu people dosen dapat mengundang mahasiswa dengan menggunakan kode akses yang telah tersedia pada bilah people, sedangkan untuk mengundang dosen lain sebagai kolaborator cukup dengan mengundang dosen melalui email masing-masing.

\section{b. Mahasiswa}

Setelah dilakukan dengan cara membuat kelas di Google Classroom terlebih dahulu oleh dosen. Kemudian mengundang mahasiswa melalui surel dari masing-masing siswa atau dapat melalui kode kelas dari Google Classroom yang telah dibuat. Secara umum, data/materi untuk pembelajaran dapat diunggah dengan menggunakan pilihan pada "About" di Google Classroom. Kemudian materi diunggah melalui "Add Materials". Untuk memberitahukan mahasiswa jika materi telah diunggah, maka dapat menggunakan pilihan "Stream" di Google Classroom, kemudian pilih "Announcement" pada "+". Untuk menambahkan tugas dapat memilih "Assigments" pada "+". Untuk menambahkan pertanyaan atau kuesioner pada Google Classroom dapat memilih "Question" pada "+". Melalui button yang dimiliki oleh Google Classroom tersebut, maka aktivitas mahasiswa dapat dilihat dari laporan yang diberikan pada kelas Google Classroom. Apabila mahasiswa telah mengunggah hasil pekerjaannya maupun hasil kuesioner yang terdapat di Google Classroom, maka ada laporan "Done" pada halaman kelas Google Classroom.

Kegiatan ini dilaksanakan dengan monitoring datang langsung ke lokasi atau via telepon, guna melihat penerapan iptek supaya tidak mengalami kesulitan dalam pelaksanaan ipteks tersebut, sehingga terjalin kerjasama yang baik dari departemen Biologi FMIPA USU dengan pihak Tim Pengabdian USU. 


\section{HASIL DAN PEMBAHASAN}

Pelaksanaan kegiatan dilakukan dengan cara penyuluhan dan ceramah, penjelasan teori dan teknik pemanfaatan Google Class Room, yang diikuti kelompok dosen dan mahasiswa. Masyarakat desa mendengarkan materi yang disampaikan oleh tim pengabdian masyarakat. Materi yang disampaikan menyangkut tentang pengunaan Google Class Room. Diharapkan akan meningkatkan pengetahuan sumberdaya manusia dalam hal Pemanfaatan Google Classroom bagi kelompok dosen dan mahasiswa. Akhirnya akan meningkatkan mutu pembelajaran dan akreditasi di departemen Biologi FMIPA USU.

Pelatihan dilakukan oleh kelompok dosen dan mahasiswa dilatih oleh tim pengabdian masyarakat. Semua melakukan kegiatan ini dengan proaktif melakukan pelatihan untuk mendapatkan hasil pemanfaatan Google Class Room. Google Classroom sebagai salah satu aplikasi yang berbasis pendidikan, tentunya sangat membantu jalannya proses belajar dan mengajar, memperlancar komunikasi antara mahasiswa dengan dosen atau dosen. Aplikasi ini juga berguna untuk mahasiswa belajar, menyimak, membaca, mengirim tugas, dari jarak jauh.

Evaluasi pelaksanaan program dan keberlanjutan program setelah selesai kegiatan ini dilaksanakan dengan monitoring datang langsung ke lokasi atau via telepon, guna melihat penerapan iptek supaya tidak mengalami kesulitan dalam pelaksanaan ipteks tersebut, sehingga terjalin kerjasama yang baik dari departemen Biologi FMIPA USU dengan pihak Tim Pengabdian USU.

\section{KESIMPULAN}

Dari kegiatan pengabdian masyarakat mengenai pemanfaatan google classroom, dapat diambil kesimpulan sebagai berikut :

1. Pemanfaatan google classroom dapat meningkatkan mutu pembelajaran di departemen Biologi.

2. Pemanfaatan google classroom dapat memberikan efektivitas dan efisiensi dalam pembelajaran.

3. Terdapat kerjasama yang baik antara USU dan Mitra.

\section{UCAPAN TERIMAKASIH}

Dalam kesempatan ini kami mengucapkan terima kasih kepada Non PNBP Tahun 2019 sebagai penyandang dana dan segenap pihak yang telah membantu dalam pelaksanaan Pengabdian Kepada Masyarakat ini. Harapan kami semoga program ini dapat berlanjut dalam memanfaat google classroom bagi dosen dan mahasiswa di departemen Biologi FMIPA USU.

\section{DAFTAR PUSTAKA}

Fadillah, Syarifah. 2009. "Kemampuan Pemecahan Masalah Matematis dalam Pembelajaran Matematika." Seminar Nasional Penelitian, Pendidikan dan Penerapan MIPA. Yogyakarta: Fakultas MIPA, Universitas Negeri Yogyakarta. 553-558.

Gunawan, Fransiskus Ivan. 2016. Mendidik Generasi Net. Yogyakarta: Sanata Dharma University Press. 
Hardiyana, Andri. 2015. Implementasi Google Classroom sebagai Alternatif dalam Meningkatkan Mutu Pembelajaran di Sekolah. Karya Tulis Ilmiah, Cirebon: SMA Negeri 1 Losari.

Indarwati, Desi, Wahyudi, dan Novisita Ratu. 2014. "Peningkatan Kemampuan Pemecahan Masalah Matematika melalui Penerapan Problem Based Learning untuk Siswa Kelas V SD." Satya Widya, Juni 1: 17-27.

Meika, Ika, dan Asep Sujana. 2017. "Kemampuan Berpikir Kreatif dan Pemecahan Masalah Matematis Siswa SMA." Jurnal Penelitian dan Pembelajaran Matematika, Agustus 2: 8-13.

Ramadhani, Rahmi. 2017. "Peningkatan Kemampuan Pemahaman Konsep dan Kemampuan Pemecahan Masalah Matematika Siswa SMA Melalui Guided Discovery Learning Berbantuan Autograph.” Jurnal Penelitian dan Pembelajaran Matematika Untirta, 2 Agustus: $72-81$.

Slavin, Roberts. 2000. Educational Psychology: Theory and Practice. New Jersey: Pearson Education.

Stein, Jared, dan Charles. R. Graham. 2014. Essentials for Blended Learning A Standards Based Guided. New York: Routledge.

Sugiyono. 2015. Metode Penelitian \& Pengembangan Research and Development. Bandung: Alfabeta.

Unaifah, Fai'q, dan Nadi Suprapto. 2014. "Profil Kemampuan Pemecahan Masalah dan Hasil Belajar Siswa pada Materi Elastisitas ditinjau dari Gaya Belajar (Learning Style)." Jurnal Inovasi Pendidikan Fisika, Maret 2: 27-32.

Viridi, Sparisoma, Jam'ah Halid, dan Tati Kristianti. 2017. "Penelitian Guru untuk Mempersiapkan Generasi Z di Indonesia." SEAMEO QITEP in Science. Bandung: P4TK IPA. 1-2.

Wahyuni, Desti, Nyayu Masyita Ariani, dan Ali Syahbana. 2013. "Kemampuan Pemecahan Masalah Matematis dan Beliefs Siswa pada Pembelajaran Open-Ended dan Konvensional." Edumatica, April 1: 35-41.

Wicaksono, Vicky Dwi, dan Rachmadyanti. 2017. "Pembelajaran Blended Learning Melalui Google Classroom di Sekolah Dasar." Seminar Nasional Pendidikan PGSD UMS \& HDPGSDI Wilayah Jawa 513-521. 